\title{
Changes of Estradiol and Lipid Concentrations in Serum and Liver Fatty Acid of Maturing Hen and Cockerel
}

\author{
Makoto Fuji, Kohji Odawara, Takao Fukunaga, \\ Katsuya KogA and Hideaki Tojo* \\ Department of Animal Science, Faculty of Agriculture, Kagoshima University, \\ Kagoshima, 890, Japan \\ *Institute of Laboratory Animal Science, Toyama Medical and \\ Pharmaceutical University, Toyama, 930-01, Japan
}

Received November 18, 1983

\begin{abstract}
Changes of the estradiol and lipid concentrations in hen serum, and those in the fatty acids of hen and cockerel livers were studied during the maturing period. The concentrations of estradiol and lipid in serum reached a maximum level a few days before the onset of laying, and then fell. A marked increase in oleate, and decreases in stearate and arachidonate were observed in both the liver and serum lipids of the hen when reaching laying. The fatty acid compositions of the serum and liver of the hen at 145 and 167 days of age were close to those of yolk lipid. In the cockerel, high contents of stearate and arachidonate and a low content of oleate were observed, and the fatty acid composition did not change appreciably with age. On estrogenization of the male chick, the fatty acid cmposition of the liver lipid was similar to that of the laying hen liver. The ratio of the unsaturated fatty acid/saturated fatty acid in the liver of hen increased when reaching laying, the value at 167 days old being close to that of yolk lipid. This ratio in the liver lipid of cockerel did not change significantly throughout the experimental period.
\end{abstract}

The laying hen produces a large amount of lipids in the liver, which are transferred into the growing oocyte via the circulation fluid for egg production. The increase in liver lipid has been demonstrated as birds approached maturity. ${ }^{1)}$ Therefore, the fatty acid composition of the liver lipid of the laying hen is considered to come close to the value for yolk lipid and to be different from that of the non-laying hen. There are, however, few reports concerning the changes in the fatty acid compositions of liver and serum lipids in the hen before and after the onset of egg production.

The synthesis of lipids in the liver of birds is markedly increased by the administration of estradiol. $^{2 \sim 7)}$ There are several reports on the change in the concentration of serum estradiol in regard to egg production, but the findings are not consistent. Common et al. ${ }^{8)}$ have reported a peak for urine estrone several days before egg production starts. Senior, ${ }^{9)}$ however, has reported a peak for serum estradiol
$2 \sim 3$ weeks before the onset of egg production. On the other hand, Tojo and Huston ${ }^{10)}$ have reported that there were two peaks for serum estradiol: a small peak at 18 weeks of age and a more distinct peak at $21 \sim 22$ weeks of age.

In this paper, we describe changes of the estradiol and lipid concentrations in the hen serum and those in the fatty acid compositions of the hen and cockerel livers on reaching sexual maturity.

\section{MATERIALS AND METHODS}

White Leghorn pullets and cockerels were housed in individual cages. They were subjected to $14 \mathrm{hr}$ light per day throughout the experiment and fed on the experimental diet shown in Table I. The diet and water were provided $a d$ libitum. The metabolizable energy of the diet was determined by a Shimadzu CA-3 Automatic Bomb calorimeter according to the formula of Hill and Anderson ${ }^{11}$ using five 30-day-old female chicks. Body weights were recorded weekly until 167 days of age, and blood samples were collected from the wing vein of each bird at weekly 
TABLE I. COMPOSITION OF THE EXPERIMENTAL DiET

$\begin{array}{lc}\text { Ingredients }(\mathrm{g} / \mathrm{kg}) & 794 \\ \text { Maize } & 42 \\ \text { Alfalfa meal } & 125 \\ \text { Soybean protein }(0.9 \text { potency) } & 2.7 \\ \text { Lysine } & 3.1 \\ \text { DL-Methionine } & 1 \\ \text { Vitamin mix* } & 32.2 \\ \text { Mineral mix** } & \\ \text { Analyses (per kg on air-dry basis) } & 128.7 \\ \text { Moisture }(\mathrm{g}) & 180.3 \\ \text { Crude protein }(\mathrm{N} \times 6.25, \mathrm{~g}) & 31.7 \\ \text { Crude fat }(\mathrm{g})^{1} & 16.2 \\ \text { Crude fiber }(\mathrm{g}) & 41.7 \\ \text { Crude ash }(\mathrm{g}) & 3132 \\ \text { Metabolizable energy }(\mathrm{kcal}) & \end{array}$

* Supplied per $\mathrm{kg}$ of diet: choline-HCl $730 \mathrm{mg}$, folic acid $0.5 \mathrm{mg}$, biotin $0.03 \mathrm{mg}$, retinol 6240 I.U., cholecalciferol 1248 I.U., $\alpha$-tocopherol $9.3 \mathrm{mg}$, menadiol $1.3 \mathrm{mg}$, riboflavin $2.5 \mathrm{mg}$, pyridoxine $0.3 \mathrm{mg}$, cobalamin $12.5 \mu \mathrm{g}$, and pantothenol $1.5 \mathrm{mg}$.

** Supplied per $\mathrm{kg}$ of diet: $\mathrm{CaCO}_{3} \cdot 6.82 \mathrm{~g}, \mathrm{CaHPO}_{4}$. $2 \mathrm{H}_{2} \mathrm{O} 21.23 \mathrm{~g}, \mathrm{NaCl} 3.63 \mathrm{~g}, \mathrm{MnSO}_{4} \cdot 5 \mathrm{H}_{2} \mathrm{O} 0.21 \mathrm{~g}$, $\mathrm{ZnSO}_{4} \cdot 7 \mathrm{H}_{2} \mathrm{O} \quad 127 \mathrm{mg}, \quad \mathrm{FeSO}_{4} \cdot 7 \mathrm{H}_{2} \mathrm{O} \quad 190 \mathrm{mg}$, $\mathrm{CuSO}_{4} \cdot 5 \mathrm{H}_{2} \mathrm{O} \quad 7.49 \mathrm{mg}, \quad \mathrm{NaIO}_{3} \quad 0.48 \mathrm{mg}$, and $\mathrm{H}_{2} \mathrm{SeO}_{3} 0.19 \mathrm{mg}$.

1 The fatty acid composition $(\%, \mathrm{w} / \mathrm{w})$ of the lipid in the diet was (carbon number: double bonds) $-14: 0$ $0.1 \%, 16: 011.3 \%, 16: 1 \quad 0.4 \%, 17: 00.1 \%, 18: 0$ $2.1 \%, 18: 127.0 \%, 18: 256.2 \%, 18: 32.0 \%, 20: 0$ $0.5 \%, 20: 10.3 \%$.

intervals. Six birds each were killed at 97, 118, 145 and 167 days of age, and the livers were removed and assayed for the lipid conent.

To study the effect of estradiol on the lipid content of the liver and on the fatty acid composition, six male chicks (15 days of age) were estrogenized with six daily subcutaneous injections of $17 \beta$-estradiol purchased from Sigma Chemical Co. $(20 \mathrm{mg} / \mathrm{kg}$ body weight $)$ in $0.1 \mathrm{ml}$ propylene glycol. The birds were killed $24 \mathrm{hr}$ after the last injection and the livers were removed. The control birds received propylene glycol alone.

Lipid analyses. Total lipids were extracted by the method of Folch et al. ${ }^{12)}$ from the lyophilized liver and serum. When the lipid was subjected to silica gel G-60 thin-layer chromatography using petroleum ether-ethyl ether-acetic acid $(80: 30: 1$, by vol.) as a developing solvent, a large amount of triacylglycerol and considerable amounts of phospholipid, diacylglycerol and cholesterol ester were detected. In this study, we examined the total lipid without fractionation. Five-tenths $\mathrm{ml}$ of benzene containing $10 \mathrm{mg}$ of lipid and $2.5 \mathrm{ml}$ of $5 \%$ hydrochloric acid in methanol were mixed in a screw capped vial, which was maintained at $90^{\circ} \mathrm{C}$ for $2 \mathrm{hr}$. The mixture was then cooled to room temperature and $5 \mathrm{ml}$ of water was added. The esters were extracted with petroleum ether $(15 \mathrm{ml} \times 3)$ and the extract was neutralized and dried for $2 \mathrm{hr}$ over a mixture of anhydrous $\mathrm{Na}_{2} \mathrm{SO}-\mathrm{Na}_{2} \mathrm{CO}_{3}(4: 1, \mathrm{w} / \mathrm{w})$. Fatty acids were analysed by a Shimadzu GC-4B chromatograph with an FID-4C flame ionization detecter (conditions: $3 \mathrm{~mm} \times 3 \mathrm{~m}$ stainless steel column packed with Unisole 3000 on Uniport C, $80 \sim 100$ mesh (Gaskuro-Kogyo, Tokyo), column temperature $230^{\circ} \mathrm{C}$, sample inlet temperature $250^{\circ} \mathrm{C}$, and carrier gas $\mathrm{N}_{2}$ with a flow rate of $44 \mathrm{ml} / \mathrm{min}$ ). The fatty acids were identified by comparing the chromatograms with those of standard samples. Peak area was determined by the peak height times half its width.

Assay of serum estradiol. The estradiol concentration in the serum was determined by a previously validated radioimmunoassay. ${ }^{10)}\left[2,4,6,7-{ }^{3} \mathrm{H}(\mathrm{N})\right]$-Estradiol was purchased from The New England Nuclear Co. (Boston, Massachusetts, U.S.A.). Rabbit antisera aginst estradiol was purchased from Teikoku-zoki Co. (Tokyo) and used at a dilution ratio of $1: 20000$. An antiserum to 6oxoestradiol-17 $\beta$-6-CMO-BSA cross-reacted $100 \%$ to estradiol- $17 \beta, 5.3 \%$ to 16 -epioestriol, $8.0 \%$ to estrone-3sulphate, $3.2 \%$ to estrone, $1.8 \%$ to estriol and $1.0 \%$ to the other 14 steroids tested. The sensitivity of the assay was $15.6 \mathrm{pg}$ of estradiol per $\mathrm{ml}$. The recoveries of estradiol from the serum were $78.5 \pm 5.8 \%(n=5)$. Dextran-coated charcoal in a phosphate-buffered saline solution was used to separate the bound and unbound steroids. The hormone concentrations of the samples were calculated in comparison with a standard curve composed of 8 points ranging from 16 to $2000 \mathrm{pg} / \mathrm{ml}$. Radioactivity was measured in a Beckman LS-3150T scintillation counter. The efficiency of ${ }^{3} \mathrm{H}$ was about $43 \%$.

Statistical analysis. Statistical significance of differences was assessed by Student's $t$-test.

\section{RESULTS AND DISCUSSION}

Changes in the concentrations of serum estradiol and lipid in the hen

The average age of the hens for the first egg production was 147 days. The serum lipid content increased on reaching sexual maturity and reached a maximum level several days before egg production started, and then fell after the onset of laying (Fig. 1) in agreement with earlier reports. ${ }^{3,13)}$ The profile of change in the concentration of serum estradiol was very similar to that of serum lipid. Each value of the serum lipid and estradiol was pooled to calculated the correlation between the concentrations of serum lipid and estradiol. The 
correlation between serum lipid and estradiol was $r=0.607(p<0.01)$. The change in serum estradiol agreed with that of urine estrone. ${ }^{8)}$ The age at which the maximum concentration of estradiol was observed in this study agreed

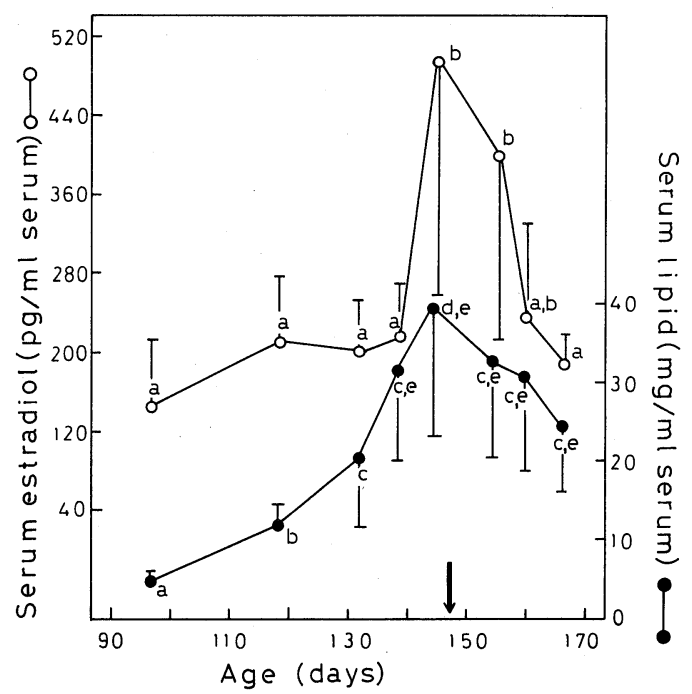

FIG. 1. Changes in Serum Lipid and Estradiol in the Hen on Reaching Egg Production.

The concentrations of estradiol and lipid in hen serum were assayed as described in the text. The results are the means of six hens and bars indicate the S.D. The arrow indicates the average age for the first egg production of the hens tested.

$\bigcirc-\mathrm{O}$, serum estradiol;

serum lipid. Values with the same superscript letters, which are grouped into estradiol and lipid, are not significantly different $(p<0.05)$. well with that for the major peak of serum estradiol in the hen. ${ }^{10)}$ In the turkey hen, the highest level of estradiol was also associated with the onset of egg production. ${ }^{14)}$ However, Senior $^{9)}$ has reported that serum estradiol reached a maximum level $2 \sim 3$ weeks before the onset of laying. Tojo and Huston ${ }^{10)}$ have reported two peaks for serum estradiol in pullets: a small peak at 18 weeks of age and a more distinct peak at $21 \sim 22$ weeks of age, just at the beginning of the egg production. The differences among these observations may be due to the wide variation in estradiol concentrations among pullets that has been reported. ${ }^{9,10,13)}$

\section{Changes in lipid contents in the livers of hen and} cockerel on reaching sexual maturity

The lipid content in the hen liver significantly increased after the onset of laying (Table II) in agreement with the report of Lorenz. ${ }^{1}$ In the cockerel, the lipid content in the liver decreased on reaching maturity.

\section{Changes in fatty acid compositions of liver and serum lipids of the hen and cockerel}

The fatty acid composition of the total lipids in liver and serum was studied. Of the major fatty acids detected, stearate and arachidonate in the liver lipid of the hen decreased on coming to laying but oleate significantly in-

Table II. Changes in Lipid Contents in the Livers of the Hen and Cockerel with Approaching Maturity

\begin{tabular}{lccccc}
\hline & $\begin{array}{c}\text { Age } \\
\text { (days) }\end{array}$ & No. & $\begin{array}{c}\text { Body wt. } \\
(\mathrm{kg})\end{array}$ & $\begin{array}{c}\text { Liver wt. } \\
(\mathrm{g})\end{array}$ & $\begin{array}{c}\text { Liver lipid } \\
(\%, \text { wet wt. })\end{array}$ \\
\hline \multirow{2}{*}{ Hen } & 97 & 6 & $1.05 \pm 0.04^{\mathrm{a}}$ & $28.61 \pm 3.37^{\mathrm{a}}$ & $5.3 \pm 0.9^{\mathrm{a}}$ \\
& 118 & 6 & $1.42 \pm 0.07^{\mathrm{b}}$ & $38.36 \pm 4.83^{\mathrm{b}}$ & $6.7 \pm 1.2^{\mathrm{b}}$ \\
& 145 & 6 & $1.54 \pm 0.08^{\mathrm{c}}$ & $38.84 \pm 4.11^{\mathrm{b}}$ & $8.8 \pm 2.2^{\mathrm{b}}$ \\
& 167 & 6 & $1.53 \pm 0.08^{\mathrm{c}}$ & $39.26 \pm 3.09^{\mathrm{b}}$ & $15.2 \pm 3.8^{\mathrm{c}}$ \\
\hline \multirow{2}{*}{ Cockerel } & 97 & 6 & $1.42 \pm 0.05^{\mathrm{a}}$ & $39.87 \pm 3.09^{\mathrm{a}}$ & $5.9 \pm 1.3^{\mathrm{a}}$ \\
& 118 & 6 & $1.51 \pm 0.09^{\mathrm{b}}$ & $35.27 \pm 3.07^{\mathrm{b}}$ & $6.3 \pm 0.3^{\mathrm{a}}$ \\
& 145 & 6 & $1.92 \pm 0.06^{\mathrm{c}}$ & $30.69 \pm 1.48^{\mathrm{c}}$ & $5.9 \pm 0.4^{\mathrm{a}}$ \\
& 167 & 6 & $2.05 \pm 0.09^{\mathrm{d}}$ & $31.05 \pm 2.45^{\mathrm{c}}$ & $5.5 \pm 0.6^{\mathrm{a}}$ \\
\hline
\end{tabular}

Values are mean \pm S.D.

Values with the same superscript letters, which are grouped into the hen and cockerel, are not significantly different $(p<0.05)$. 
Table III. Fatty Acid Composition ( $\%$, w/w) of the Hen Liver and Serum Lipids on Reaching Egg Production

\begin{tabular}{|c|c|c|c|c|c|c|c|c|}
\hline & & \multicolumn{7}{|c|}{ Fatty acid (carbon number: double bonds) } \\
\hline & & $14: 0$ & $16: 0$ & $16: 1$ & $18: 0$ & $18: 1$ & $18: 2$ & $20: 4$ \\
\hline \multirow[t]{4}{*}{ Liver } & $97(6)$ & $0.4 \pm 0.1$ & $28.2 \pm 1.9^{\mathrm{a}}$ & $2.4 \pm 1.1$ & $19.9 \pm 2.1^{\mathrm{a}}$ & $28.3 \pm 5.1^{\mathrm{a}}$ & $12.7 \pm 2.3^{\mathrm{a}}$ & $8.0 \pm 2.9^{\mathrm{a}}$ \\
\hline & $118(6)$ & $0.4 \pm 0.1$ & $27.3 \pm 1.3^{\mathrm{a}, \mathrm{b}}$ & $2.4 \pm 0.4$ & $18.4 \pm 1.8^{\mathrm{a}, \mathrm{b}}$ & $31.8 \pm 3.7^{\mathrm{a}}$ & $12.3 \pm 1.4^{\mathrm{a}}$ & $7.3 \pm 1.9^{\mathrm{a}}$ \\
\hline & $145(6)$ & $0.3 \pm 0.1$ & $26.3 \pm 1.9^{\mathrm{a}, \mathrm{b}}$ & $2.6 \pm 0.6$ & $15.0 \pm 3.7^{b, c}$ & $32.9 \pm 4.3^{\mathrm{a}}$ & $16.1 \pm 4.3^{\mathrm{a}}$ & $5.9 \pm 0.9^{\mathrm{a}}$ \\
\hline & $167(6)$ & $0.5 \pm 0.1$ & $25.3 \pm 3.0^{\mathrm{b}}$ & $3.4 \pm 0.7$ & $11.3 \pm 1.0^{\mathrm{c}}$ & $40.6 \pm 3.0^{b}$ & $15.3 \pm 4.8^{\mathrm{a}}$ & $3.3 \pm 2.6^{b}$ \\
\hline \multirow[t]{4}{*}{ Serum } & $97(6)$ & $0.4 \pm 0.0$ & $24.5 \pm 1.3^{\mathrm{a}}$ & $2.4 \pm 0.9$ & $15.7 \pm 2.3^{\mathrm{a}}$ & $26.9 \pm 3.1^{\mathrm{a}}$ & $20.8 \pm 2.5^{\mathrm{a}}$ & $7.0 \pm 2.2^{\mathrm{a}}$ \\
\hline & $118(6)$ & $0.4 \pm 0.1$ & $26.4 \pm 1.1^{\mathrm{a}}$ & $2.3 \pm 0.3$ & $14.9 \pm 2.1^{\mathrm{a}}$ & $32.2 \pm 5.7^{\mathrm{a}}$ & $17.0 \pm 1.7^{\mathrm{b}}$ & $6.7 \pm 4.0^{\mathrm{a}, \mathrm{b}}$ \\
\hline & $145(6)$ & $0.3 \pm 0.0$ & $27.0 \pm 1.6^{\mathrm{a}}$ & $3.5 \pm 0.5$ & $10.1 \pm 1.3^{\mathrm{b}}$ & $43.3 \pm 2.9^{b}$ & $12.4 \pm 2.8^{\mathrm{c}}$ & $3.2 \pm 2.0^{\mathrm{b}, \mathrm{c}}$ \\
\hline & $167(7)$ & $0.4 \pm 0.1$ & $26.9 \pm 1.8^{\mathrm{a}}$ & $2.9 \pm 0.7$ & $11.8 \pm 1.8^{\mathrm{b}}$ & $40.3 \pm 2.4^{b}$ & $15.2 \pm 1.2^{\mathrm{d}}$ & $2.6 \pm 1.3^{\mathrm{c}}$ \\
\hline Egg yolk ${ }^{1}$ & & 0.4 & 28.2 & 3.5 & 10.4 & 42.2 & 13.3 & 1.9 \\
\hline
\end{tabular}

Values are mean \pm S.D.

Values with the same superscript letters, which are grouped into liver and serum, are not significantly different $(p<0.05)$.

1 Mean of three assays of six pooled eggs laid by the hens.

Table IV. Fatty Acid Composition of Liver Lipid in the Cockerel Approaching Maturity

\begin{tabular}{|c|c|c|c|c|c|c|c|c|c|c|c|}
\hline \multirow{2}{*}{$\begin{array}{c}\text { Age } \\
(\text { days) }(n)\end{array}$} & \multicolumn{11}{|c|}{ Fatty acid (carbon number: double bonds), $(\%, w / w)$} \\
\hline & $14: 0$ & $16: 0$ & $16: 1$ & $17: 0$ & $18: 0$ & $18: 1$ & $18: 2$ & $20: 1$ & $20: 2$ & $20: 3$ & $20: 4$ \\
\hline $97(6)$ & $0.4 \pm 0.1$ & $29.4 \pm 2.3^{\mathrm{a}}$ & $2.1 \pm 0.4$ & trace & $23.0 \pm 2.0^{\mathrm{a}}$ & $23.8 \pm 3.8^{\mathrm{a}}$ & $13.3 \pm 1.0^{\mathrm{a}}$ & trace & $0.1 \pm 0.2$ & $1.0 \pm 0.5$ & $6.9 \pm 1.1^{\mathrm{a}}$ \\
\hline $118(6)$ & $0.3 \pm 0.1$ & $23.1 \pm 2.9^{b}$ & $2.2 \pm 0.6$ & $0.1 \pm 0.0$ & $24.0 \pm 1.1^{\mathrm{a}}$ & $22.5 \pm 3.2^{\mathrm{a}}$ & $16.1 \pm 2.0^{b}$ & $0.2 \pm 0.2$ & $0.3 \pm 0.3$ & $1.9 \pm 0.9$ & $9.4 \pm 2.2^{\mathrm{b}}$ \\
\hline $145(6)$ & $0.2 \pm 0.0$ & $23.5 \pm 1.8^{\mathrm{b}}$ & $1.0 \pm 0.2$ & $0.3 \pm 0.1$ & $27.5 \pm 0.7^{b}$ & $13.8 \pm 1.3^{\mathrm{b}}$ & $18.7 \pm 1.7^{\mathrm{c}}$ & $0.2 \pm 0.2$ & $0.5 \pm 0.2$ & $1.1 \pm 0.2$ & $13.2 \pm 0.9^{\mathrm{c}}$ \\
\hline $167(6)$ & $0.3 \pm 0.1$ & $24.4 \pm 3.8^{\mathrm{b}}$ & $2.7 \pm 1.8$ & $0.2 \pm 0.1$ & $24.8 \pm 2.2^{\mathrm{a}}$ & $21.0 \pm 4.2^{\mathrm{a}}$ & $16.0 \pm 2.3^{\mathrm{a}, \mathrm{b}, \mathrm{c}}$ & $0.5 \pm 0.2$ & $0.9 \pm 0.5$ & $1.3 \pm 0.5$ & $8.4 \pm 2.7^{\mathrm{a}, \mathrm{b}}$ \\
\hline
\end{tabular}

Values are mean \pm S.D.

Values with the same superscript letters are not significantly different $(p<0.05)$. 
creased at the same stage (Table III). The profile of changes in the fatty acid composition of the serum lipid was similar to that of liver lipid. A large increase in oleate and a large decrease in stearate were observed in the serum lipid of the hen at 145 days of age, suggesting that a marked alteration in the lipid metabolism occurred in the hen several days before the onset of laying. Linoleate in the serum and liver lipids showed a slight change. After the onset of egg production, the fatty acid compositions of the liver and serum lipids came close to the values for egg yolk from the hen. The fatty acid composition of the serum lipid was assayed at 97, 118, 132, 139, 145, 153, 160 and 167 days of age, and the data for 97,118 , 145 and 167 days are shown in Table III to compare with those of liver lipids. Each of the major fatty acids from 97- to 167-day hens (97, $118,132,139,145,153,160$ and 167 days) was pooled to calculate the correlations between the concentration of serum estradiol and fatty acids. The correlations between estradiol and stearate, oleate, linoleate and arachidonate were $r=-0.30 \quad(p<0.05), 0.417 \quad(p<0.01)$, $-0.447(p<0.01)$, and $-0.239(p<0.05)$, respectively. No correlation was observed between estradiol and palmitate.

In cockerel liver, the fatty acid composition at 167 days of age was almost the same as that of 97-day-old cockerel, except for the low content of palmitate (Table IV). The cockerel showed a reverse change in the fatty acid composition at 145 days of age compared with the hen, namely increases in stearate and arachidonate and a decrease in oleate were observed. Similar changes in the fatty acid composition were observed in testosteronetreated chicks. $\left.{ }^{15}\right)$ These findings suggest that the concentration of testosterone in the liver of cockerel increased several days before sexual maturity.

Upon estrogenization of the male chicks, the liver lipid content was more than twice that of the control chicks, and the serum lipid markedly rose (Table V) in agreement with earlier observations. $^{2 \sim 7,16,17)}$ The compositions of stearate and polyenoic acids significantly decreased but that of oleate markedly increased in the liver and serum lipids (Table VI). Linoleate in the serum lipid decreased in estro-

TABle V. EfFect of a 6-Day Course of $17 \beta$-Estradiol on Male Chicks

\begin{tabular}{lcc}
\hline & $\begin{array}{c}\text { Control } \\
\text { birds } \\
(n=6)\end{array}$ & $\begin{array}{c}\text { Estrogenized } \\
\text { birds } \\
(n=6)\end{array}$ \\
\hline Food intake, g & $144 \pm 8$ & $164 \pm 14$ \\
Body wt. gain, g & $64 \pm 5$ & $65 \pm 10$ \\
Liver wt. g/100 g body wt. & $4.4 \pm 0.4$ & $7.2 \pm 1.1^{* *}$ \\
Liver lipid, \%, wet wt. & $5.1 \pm 0.3$ & $11.8 \pm 4.2^{* *}$ \\
Serum lipid, mg/ml serum & $14.1 \pm 1.4$ & $131.7 \pm 9.4^{* *}$ \\
\hline
\end{tabular}

Average initial body weights for the control and estrogenized birds were $118 \mathrm{~g}$ and $114 \mathrm{~g}$, respectively. Values are mean \pm S.D.

** Significant at $p<0.01$.

Table VI. Effect of a 6-Day Course of Estradiol on Fatty Acid Compositions of Serum and Liver Lipids in Male Chicks

\begin{tabular}{|c|c|c|c|c|c|c|c|c|}
\hline & \multicolumn{8}{|c|}{ Fatty acid (carbon number: double bonds), $(\%, w / w)$} \\
\hline & $14: 0$ & $16: 0$ & $16: 1$ & $18: 0$ & $18: 1$ & $18: 2$ & $20: 3$ & $20: 4$ \\
\hline \multicolumn{9}{|l|}{ Liver } \\
\hline Control & $0.3 \pm 0.0$ & $32.2 \pm 1.7$ & $3.3 \pm 0.7$ & $19.1 \pm 0.8$ & $23.5 \pm 2.1$ & $13.0 \pm 1.4$ & $2.1 \pm 0.7$ & $6.6 \pm 2.0$ \\
\hline Estrogenized & $0.3 \pm 0.1$ & $29.5 \pm 2.9$ & $3.8 \pm 0.6$ & $11.6 \pm 1.5^{* *}$ & $42.5 \pm 3.8 * *$ & $10.0 \pm 2.0^{*}$ & trace & $2.2 \pm 1.2 * *$ \\
\hline \multicolumn{9}{|l|}{ Serum } \\
\hline Control & $0.4 \pm 0.2$ & $28.4 \pm 3.5$ & $2.3 \pm 0.5$ & $17.2 \pm 2.5$ & $24.5 \pm 3.6$ & $23.3 \pm 3.6$ & $0.3 \pm 0.1$ & $3.3 \pm 1.7$ \\
\hline Estrogenized & $0.4 \pm 0.0$ & $30.4 \pm 3.4$ & $3.4 \pm 0.8$ & $8.4 \pm 1.8^{* *}$ & $44.6 \pm 2.4^{* *}$ & $10.4 \pm 0.7^{* *}$ & trace & $0.9 \pm 0.3^{* *}$ \\
\hline
\end{tabular}

Values are mean \pm S.D. $(n=6)$.

* Significant at $p<0.05$.

** Significant at $p<0.01$. 
genized birds. When estradiol was administered, the fatty acid composition of the liver lipid of the male chick approached that of the laying hen at 167 days of age, showing that estradiol affects the fatty acid composition in the liver lipid. Chung et al. ${ }^{4)}$ and Balnave ${ }^{15)}$ have reported similar observations, except for the change in arachidonate.

Lippello et al. ${ }^{18)}$ have reported that estradiol increased the stearyl-CoA desaturase activity, and that, as a result, the content of oleate increased and that of stearate decreased. The concentration of estradiol markedly increased in hen just before the onset of laying (Fig. 1). Therefore, the increase in oleate and the decrease in stearate that were observed in the laying hen may be due to an increase in the stearyl-CoA desaturase activity. The reason for the changes in fatty acid compositions, which were observed in male chicks upon estrogenization, is probably quite similar.

\section{Molar ratio of unsaturated to saturated fatty acids}

The molar ratio of the unsaturated to saturated fatty acids in the liver lipid of the hen increased towards the onset of egg production (Table VII). The ratio with 167-day hens was about 1.6 times that of 97-day hens, and reached a level similar to that of the egg yolk lipid. The molar ratio in the cockerel liver did not change as sexual maturity approached, and the value was smaller than 1.0 , indicating that the unsaturated fatty acid content in the cockerel liver was less than that in the hen liver.

\section{Relationships between stearate, oleate and linoleate}

The proportions of stearate and oleate markedly changed approaching the egg production stage in the hen, and 18-carbon fatty acid contents were high in the total fatty acids of the liver lipid. Therefore, the relationships between stearate, oleate and linoleate were examined (Fig. 2). The laying hens (167-day) had a high content of oleate and a low content of stearate, and showed a distinct pattern in
Table VII. Change in Molar Ratio of Unsaturated to Saturated FatTy ACIDS

\begin{tabular}{|c|c|c|c|}
\hline & & \multicolumn{2}{|c|}{$\begin{array}{l}\text { Molar ratio of unsaturated } \\
\text { saturated fatty acid }\end{array}$} \\
\hline & & Hen & Cockerel \\
\hline \multirow[t]{4}{*}{ Age (days) } & 97 & 1.00 & 0.84 \\
\hline & 118 & 1.10 & 1.05 \\
\hline & 145 & 1.30 & 0.89 \\
\hline & 167 & 1.58 & 0.97 \\
\hline \multicolumn{4}{|l|}{ Male chick } \\
\hline \multicolumn{2}{|c|}{ Control } & \multicolumn{2}{|c|}{0.88} \\
\hline \multicolumn{2}{|c|}{ Estrogenized } & \multicolumn{2}{|c|}{1.32} \\
\hline \multicolumn{2}{|c|}{ Egg yolk } & \multicolumn{2}{|c|}{1.46} \\
\hline
\end{tabular}

Values were calculated on the means of the fatty acid compositions of the groups.

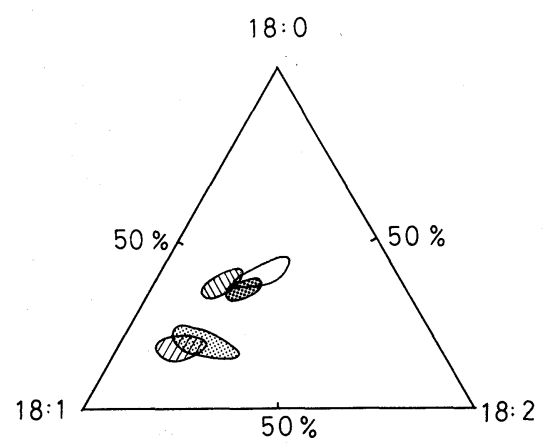

FIG. 2. The Distribution of Hen and Cockerel at Different Stages on the Basis of the Ratio of the Fatty Acid Compositions of Stearate $(18: 0)$, Oleate $(18: 1)$ and Linoleate $(18: 2)$.

The respective corners of the triangle comprise $100 \%$ of $18: 0,18: 1$ and $18: 2$, respectively.

M. 97-day hens; day cockerels; WIZA, estrogenized male chicks; control male chicks.

the distribution of 18-carbon fatty acids when compared with the non-laying hens (97-day). The cockerels of 97 and 167 days old showed a similar pattern in the distribution of fatty acids, showing that no alteration in 18-carbon fatty acid composition occurred with age. The control male chicks showed a simialr distribution pattern of fatty acid to those of cockerels (97 and 167 days old). Upon estrogenization of the male chicks, a high content of oleate and a low content of stearate were observed. The estrogenized birds, therefore, 
showed a similar distribution pattern of fatty acids to that of the laying hens (167 days old). The distribution patterns of 18-carbon fatty acid compositions described above are apparently classified into two groups. One group comprises the laying hens and estrogenized birds, and the other is composed of the nonlaying and male birds. The laying hens and estrogenized birds contain a larger amount of triacylglycerol than phospholipid in the liver. $^{1,19)}$ Further studies are necessary to learn the possible relationships between the distribution pattern of fatty acid and the contents of triacylglycerol and phospholipid.

Acknowledgments. We are grateful to Dr. Y. Tomita and Dr. K. Hayashi (Faculty of Agriculture, Kagoshima University) for their kind direction in calculating metabolizable energy and to Miss M. Ohyama for her help in this work.

\section{REFERENCES}

1) F. W. Lorenz, I. L. Chaikoff and C. Entenman, J. Biol. Chem., 123, 577 (1938).

2) A. Taurog, F. W. Lorenz, C. Entenman and I. L. Chaikoff, Endocrinology, 35, 483 (1944).

3) P. J. Heald and K. A. Rookledge, J. Endocrinol.,
30, 115 (1964).

4) R. A. Chung, J. M. J. Ning and Y. C. Tsao, Poultry Sci., 45, 661 (1966).

5) R. A. Hawkins and P. J. Heald, Biochim. Biophys. Acta, 116, 41 (1966).

6) D. J. Kudzma, F. St. Claire, L. DeLallo and S. J. Friedberg, J. Lipid Res., 16, 123 (1975).

7) R. Coleman, M. A. Polokoff and R. M. Bell, Metabolism, 26, 1123 (1977).

8) R. H. Common, L. Ainsworth, F. Hertelendy and R. S. Mathur, Can. J. Biochem., 43, 539 (1965).

9) B. E. Senior, J. Reprod. Fert., 41, 107 (1974).

10) H. Tojo and T. M. Huston, Poultry Sci., 59, 2797 (1980).

11) F. W. Hill and D. L. Anderson, J. Nutr., 64, 587 (1958).

12) J. Folch, M. Lees and G. H. Sloanestanley, J. Biol. Chem., 226, 497 (1957).

13) P. J. Heald and H. G. Badman, Biochim. Biophys. Acta, 70, 381 (1963).

14) M. J. Wineland and B. C. Wentworth, Poultry Sci., 54, 381 (1975).

15) D. Balnave, Comp. Biochem. Physiol., 28, 709 (1969).

16) R. E. Ranney and I. L. Chaikoff, Am. J. Physiol., 165, 600 (1951).

17) S. Hasegawa, T. Niimori, K. Sato, Y. Hikami and T. Mizuno, Jpn. J. Zootech. Sci., 53, 699 (1982).

18) P. M. Lippiello, C. T. Holloway, S. A. Garfield and P. W. Holloway, J. Biol. Chem., 254, 2004 (1979).

19) D. Balnave, J. Endocrinol., 42, 119 (1968). 